\title{
Análise Comparada do Fluxo do Sistema de Justiça para o Crime de Estupro
}

Joana Domingues Vargas

\begin{abstract}
produção nacional sobre a aplicação da Justiça para o crime de esA tupro é pequena e caracteriza-se por limitar a investigação a uma etapa do processamento penal. Esta produção distingue-se também por um certo etnocentrismo, tendo em vista as pouquíssimas comparações efetuadas entre os resultados aqui encontrados e aqueles obtidos em pesquisas realizadas em outros países. Conseqüentemente, os padrões e as tendências nacionais identificados têm sido interpretados como singulares e, muitas vezes, atribuídos exclusivamente à incapacidade e à ineficiência das nossas polícia e Justiça para lidar com as demandas da sociedade.
\end{abstract}

Neste artigo, objetivo mostrar as vantagens de se privilegiar a análise do fluxo da produção decisória no processamento de determinado crime e de se proceder à comparação dos resultados obtidos em pesquisas empíricas realizadas em diferentes países. Para tanto, valer-me-ei do estudo por mim realizado sobre o fluxo da Justiça Criminal para o crime de estupro em Campinas (Vargas, 2000; 2004) e do estudo de LaFree $(1981 ; 1989)$ sobre o tratamento dado ao estupro na Justiça Criminal norte-americana, realizado com base em dados levantados em Indianápolis ${ }^{1}$.

Boa parte dos estudos internacionais sobre o tratamento dado ao estupro na Justiça acompanha os desenvolvimentos teóricos dos estudos

DADOS - Revista de Ciências Sociais, Rio de Janeiro, Vol. 50, n-4 4, 2007, pp. 671 a 697. 
sobre decisão na Justiça Criminal em geral e buscam, cada vez mais, verificar a interação das chamadas variáveis legais, extralegais e de processamento (organizacionais) no resultado das decisões².

Contudo, de todas estas variáveis, as ditas legais são as menos problematizadas (Pires e Landreville, 1985) ${ }^{3}$. Caberia então perguntar: regras jurídicas (de incriminação e de decisão) equivaleriam a regras e nor-

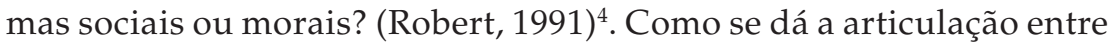
normas morais e regras legais? Estas questões têm recebido especial atenção nos países de Civil Law Tradition (França e Bélgica, dentre outros), tendo em vista a importância dada às regras de incriminação (substantiva) e de decisão (processual) nesta tradição. Considerando a importância conferida no sistema de direito brasileiro às regras codificadas e o fato de que o sistema criminal não se baseia na negociação como princípio de administração dos conflitos, mas funda-se na descoberta da verdade (Kant de Lima, 1997), interessa saber: qual o peso das regras jurídicas no sistema de Justiça Criminal brasileiro para a atividade de subsunção dos casos de estupro e em que medida elas orientam e delimitam as decisões na Justiça?

O propósito deste estudo é oferecer alguma contribuição para o conhecimento da Justiça Criminal brasileira: de um lado, da sua capacidade em identificar, processar e punir agressões sexuais e, de outro, da importância que esta confere, no processamento do estupro, às regras legais formais, relativamente à Justiça Criminal americana.

\section{O FLUXO DO SISTEMA DE JUSTIÇA CRIMINAL}

Foi dito que a forma mais adequada de investigar a resposta que o sistema de Justiça Criminal oferece aos eventos sexuais, que são submetidos a sua repressão, é reconstituir o fluxo de pessoas e procedimentos que atravessam as diferentes organizações que compõem este sistema - polícia, Ministério Público, varas criminais, Tribunal de Apelação, Departamento Penitenciário (Coelho, 1986; Fundação João Pinheiro, 1987; Vargas, 2000).

Esta reconstituição não é tarefa fácil, nem mesmo em países como os Estados Unidos, que possuem, desde a década de 1930, um sistema uniformizado de contabilidade das ocorrências criminais e de sua repressão - os Uniform Crime Reporting - UCR -, integrando, em âmbito nacional, as estatísticas oficiais provenientes da polícia e da Justiça. 
Um dos problemas encontrados para a reconstituição desse fluxo é a dificuldade de articulação das informações sobre o processamento dos casos e dos agressores de forma a garantir seu acompanhamento no tempo. LaFree chama a atenção para isso:

\begin{abstract}
“Em Indianápolis, a polícia e as cortes atribuem números diferentes de identificação para os mesmos casos. Assim, o único jeito de combinar os dados da polícia com os das cortes consiste em comparar os conteúdos dos casos, individuais. Em muitos casos, isto requer um simples emparelhamento dos nomes dos agressores nos dados da polícia e das cortes. Em se tratando de nomes comuns, é necessário comparar outras características do caso para garantir uma combinação acurada" (LaFree, 1989:92, tradução da autora).
\end{abstract}

O nome do acusado é, portanto, a peça-chave para a montagem do fluxo. Esta constatação nos é revelada também no meu estudo, já referido, sobre crimes sexuais e sistema de justiça (Vargas, 2000). Assim, o acompanhamento praticamente individualizado dos casos explica o caráter localizado da grande maioria dos estudos desta natureza, realizados a partir de bases de dados relativamente pequenas. Este enfoque localizado e a desarticulação das informações, observados nos dois países, parecem ser um forte indicador de um certo grau de autonomia organizacional dos vários subsistemas ${ }^{5}$.

Apesar das diferenças nas tradições legais dos dois países - Brasil e Estados Unidos - e da diversidade de instituições, regras e procedimentos existentes em seus sistemas de justiça ou, ainda, de práticas nacionais mais ou menos institucionalizadas, como, por exemplo, a existência de mecanismos de negociação como o plea bargainning no sistema americano, a comparação entre os resultados desses estudos é possível e proveitosa, uma vez que eles privilegiam mais ou menos os mesmos estágios de decisão.

Começarei, então, apresentando os dados absolutos e as porcentagens referentes às diferentes etapas de decisão, bem como a proporção dos casos que alcançam uma condenação dentre aqueles que dão entrada no sistema, em ambos os estudos. Antes de prosseguir, porém, gostaria de retomar algumas considerações sobre o fluxo da Justiça Criminal em geral e para o crime de estupro em particular, tendo em vista um melhor entendimento do tema em foco. 
O fluxo da Justiça Criminal apresenta uma forma de funil. Inicia-se com um grande número de casos reportados à polícia e termina, depois de seleções sucessivas, com um pequeno número de casos sentenciados. Este efeito de funil é uma característica inerente aos sistemas de Justiça Criminal modernos e se apresenta para todos os tipos de ocorrências criminais ${ }^{6}$.

Se, de acordo com os códigos e com as atividades práticas dos operadores da Justiça Criminal, para cada tipo de delito corresponde uma maneira singular de tratamento dos casos, pode-se pensar que a natureza do delito intervém de maneira decisiva na configuração que o fluxo assume. Partindo deste pressuposto, comparar fluxos de diferentes crimes é menos elucidativo do que comparar fluxos de crimes de mesma natureza, tratados por diferentes sistemas de Justiça.

Estudos sobre o funcionamento da Justiça Criminal realizados em diferentes países convergem ao apontar que a atuação desta é marcada muito mais por uma ação reativa do que proativa ${ }^{7}$. No caso da repressão ao estupro, prevalece a primeira, ou seja, o sistema reage após ser acionado e, só então, passa a proceder à seleção e ao processamento dos casos e de seus autores (LaFree, 1989). No Brasil, esta reação encontra-se também definida nos códigos, na natureza da ação penal. Isto é, em crime de estupro, exceto em alguns casos, a decisão de acionar o sistema é de natureza privada.

Finalmente, nunca é demais lembrar que as informações produzidas pelo sistema de Justiça Criminal não são um indicador da ocorrência da criminalidade, mas antes da repressão exercida sobre ela por este sistema, pois ficam de fora desta contabilidade os casos que não foram levados ao conhecimento da polícia. É sabido que em crimes sexuais é alto o índice de casos em que as vítimas não apresentam denúncia, atribuído a um padrão de comportamento de grande parte das pessoas vitimadas - o silêncio ou a resolução do conflito no âmbito privado.

\section{Fluxo de Funcionamento da Justiça para o Crime de Estupro em Campinas}

Em contraste com outros países, principalmente os de língua inglesa, o Brasil tem pouca tradição de estudos empíricos sobre a aplicação da Justiça, e poucos são aqueles que utilizam o modelo de fluxo para o estudo do funcionamento da Justiça Criminal ${ }^{8}$. $\mathrm{Na}$ área dos estudos de gênero e justiça, são raros os trabalhos que seguem esta orientação me- 
todológica. Os dados apresentados na grande maioria das pesquisas sobre o tratamento dado pela Justiça Criminal à violência contra a mulher, à violência doméstica e, mais especificamente, à violência sexual limitam-se a alguma fase do processamento penal, seja a policial (Azevedo e Guerra, 1988; Feiguin et alii, 1987; Soares, 1996; Saffioti, 1994), seja a judicial (Corrêa, 1983; Pimentel, Schritzmeyer e Pandjiarjian, 1998). Apenas recentemente algumas pesquisas têm buscado a reconstituição do fluxo da produção decisória da Justiça Criminal em todas as suas fases. Especificamente em relação ao crime de estupro, até o momento, o presente estudo é o único que se propôs a fazer tal reconstituição e a quantificar esse fluxo de decisões ${ }^{9}$. Para tanto, foram analisados 444 Boletins de Ocorrência - BOs de estupros registrados na Delegacia de Defesa da Mulher - DDM de Campinas no período entre 1988 e 1992 e verificados os seus desdobramentos (incluindo o seu arquivamento) no fluxo procedimental da Justiça até o ano de 2001.

No Estado de São Paulo, o registro de uma ocorrência criminal, denominado boletim de ocorrência, é elaborado na Polícia Civil no momento em que a vítima ou a pessoa responsável pela queixa procura a delegacia ou é a ela encaminhada por policiais militares. Em Campinas, a averiguação de crimes de estupro e de outros crimes cometidos contra a mulher é feita, desde 1988, pela delegacia de defesa desta ${ }^{10}$. A instauração de um inquérito policial em caso de estupro resulta de um conjunto de decisões. A primeira delas ocorre com a identificação da ocorrência criminal pela autoridade policial, com base, inicialmente, nas informações dos BOs, no laudo de exame de corpo de delito e, posteriormente, nos depoimentos dos envolvidos. O procedimento seguinte consiste em submeter a vítima e seu representante legal à decisão de iniciar a ação penal. Nas ocorrências em que não existem indícios suficientes de autoria não é oferecida a denúncia, e a queixa acaba arquivada na delegacia. Das 444 queixas iniciais de estupro registradas em BOs na DDM de Campinas, apenas 128 foram transformadas em inquéritos.

A responsabilidade da ação penal que dá origem à denúncia é do Ministério Público, quando pública, ou do representante legal do ofendido, quando privada. Vimos que, em caso de estupro, salvo condições especiais, a ação é privada. De acordo com o Código Penal, uma ação privada pode tornar-se pública caso os queixosos aleguem não poder arcar com as custas do processo. Na prática observada na DDM de Campinas, quase todas, se não todas, as ações tornaram-se de iniciati- 
va do Ministério Público, ou seja, nos 71 casos de estupro denunciados, a ação partiu do promotor.

Com a denúncia, inicia-se a instrução criminal, que consiste em vários ritos nos quais são ouvidos réus e testemunhas e se manifestam o Ministério Público e a Defesa. Ao final, o juiz pronuncia-se por meio da sentença. Dos 71 casos denunciados, 41 receberam sentença condenatória, 25 tiveram sentença absolutória, em três casos o réu era revel e, em dois não foi possível saber o desfecho.

Das sentenças de condenação ou de absolvição cabe a apelação do promotor, do querelante ou da Defesa. Se aceita, os autos são julgados por um Tribunal de Segunda Instância. De acordo com os dados levantados, em 24 casos houve apelação. Destes, em sete a condenação foi mantida, em 10 ela foi diminuída, um caso de condenação em primeira instância obteve absolvição na segunda e dois casos de absolvição resultaram em condenação no Tribunal.

Conforme o previsto (Gráfico 1), o fluxo do crime de estupro, em Campinas, inicia-se com uma grande base para, em seguida, assumir a forma de um funil. O que mais chama a atenção é a grande filtragem operada na fase policial, quando $71 \%$ dos $\mathrm{BOs}$ iniciais são arquivados. Uma segunda seleção ocorre antes da fase judicial. Nesta, prosseguem $55 \%$ dos inquéritos instaurados. Dos casos denunciados, $58 \%$ resultam em condenação, mas esta porcentagem representa apenas $9 \%$ dos re-

\section{Gráfico 1}

Fluxo do Estupro em Campinas

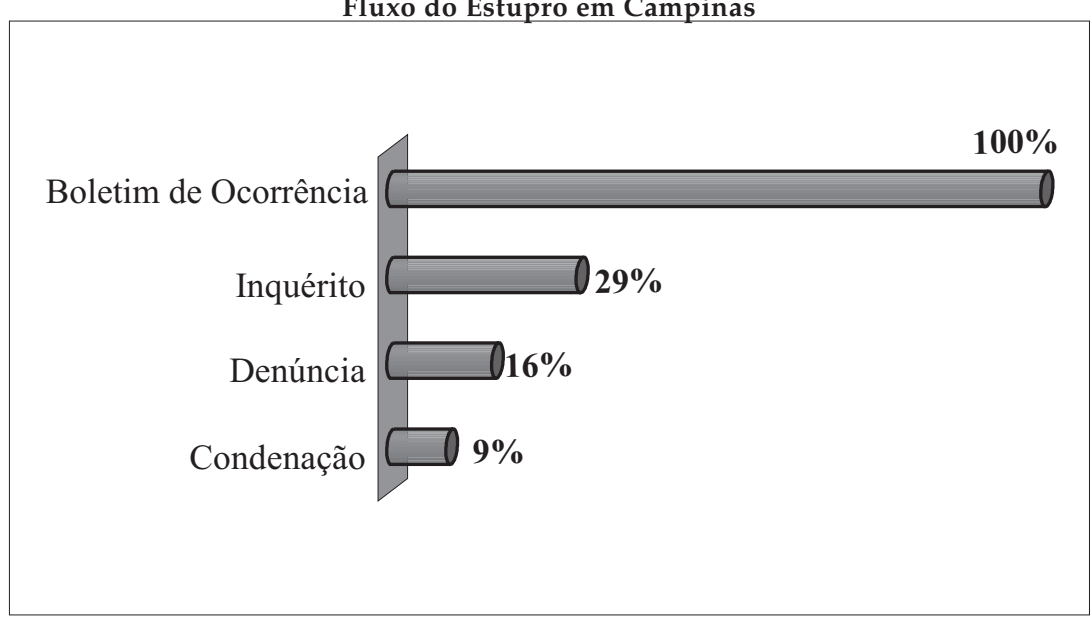

Fontes: DDM e Fórum de Campinas. 
gistros iniciais. Portanto, verifica-se uma baixa probabilidade de condenação dos casos que deram entrada no sistema.

Por si sós, os dados nos mostram que a fase policial é a de maior filtragem dos casos e que há uma probabilidade muito baixa de condenação desses casos que deram entrada no sistema (menos de 10\%). Portanto, pode-se concluir que a punição para este tipo de crime é bastante remota. Surge, então, a pergunta: a dificuldade de passagem da queixa à configuração jurídica do crime e a impunidade em relação ao estupro são características singulares do país que devem ser atribuídas às nossas agências responsáveis pela repressão a este crime? Para responder a esta pergunta, valer-me-ei dos dados apresentados na pesquisa de LaFree (1989) sobre o fluxo da Justiça para o crime de estupro realizada em Indianápolis e proceder a um exercício comparativo dos seus resultados.

\section{Fluxo de Funcionamento da Justiça para o Crime de Estupro em Indianápolis}

Em meados da década de 1970 - na esteira dos movimentos feministas, do interesse da criminologia pelo poder dos grupos dominantes na aplicação da lei e pelo processo de construção social do crime, em especial daquele desempenhado pelas agências de controle social - surgiram, nos Estados Unidos, as primeiras pesquisas buscando avaliar o tratamento dado pela Justiça Criminal ao estupro. O trabalho de LaFree (idem) inscreve-se neste contexto e continua sendo o estudo mais completo e importante realizado sobre o tema. Conforme o proposto, passo, a seguir, a descrever a base de dados e o fluxo reconstituído por este autor.

A base de dados do estudo de LaFree compõe-se de 881 casos de estupro reportados à polícia, em Indianápolis, em 1970, 1973 e 1975 e seus desfechos, incluindo dados coletados nas cortes, de julho de 1978 a setembro de 1980, e dados de entrevistas com policiais, promotores, advogados, jurados e juízes, que processaram os casos incluídos no estudo.

Os 881 casos iniciais de estupro referem-se aos registros dos oficiais despachados à cena quando solicitados através de demanda ou às ocorrências reportadas diretamente à polícia. Destes, 328 resultaram em arrest, ou seja, foram submetidos à investigação da polícia, que decidiu prender o suspeito. Os outros foram arquivados, ou porque a 
queixa foi considerada infundada, ou porque o suspeito não foi identificado ou, ainda, porque a vítima não quis cooperar na investigação.

As detenções por ofensas potencialmente sérias são revistas por advogados da Promotoria (felony screener), em consulta aos investigadores. Os advogados examinadores procuram verificar a seriedade do caso, se há elementos de prova, se a vítima vai testemunhar, e decidem-se por uma das quatro opções:

- arquivar o caso, por verificarem que não há evidências suficientes;

- encaminhá-lo para a Corte Municipal, quando consideram a ofensa menor ou que a vítima não irá testemunhar;

- apresentar o caso ao Grand Jury, quando há problemas com evidências;

- enviar o caso diretamente para a Corte Criminal, preservando a acusação inicial.

Após esta seleção, 153 casos foram encaminhados como crime (felony charged). Destes, 125 tiveram a sua denúncia (prosecution) estabelecida, sendo que 74 casos resultaram em guilty plea e 50 foram julgados por tribunal ${ }^{11}$. Em 104 casos, o réu foi considerado culpado e, em 83, foi decretada a sentença de execução. Em 42 casos, esta teve de ser cumprida em penitenciária.

Gráfico 2

O Fluxo do Estupro em Indianápolis

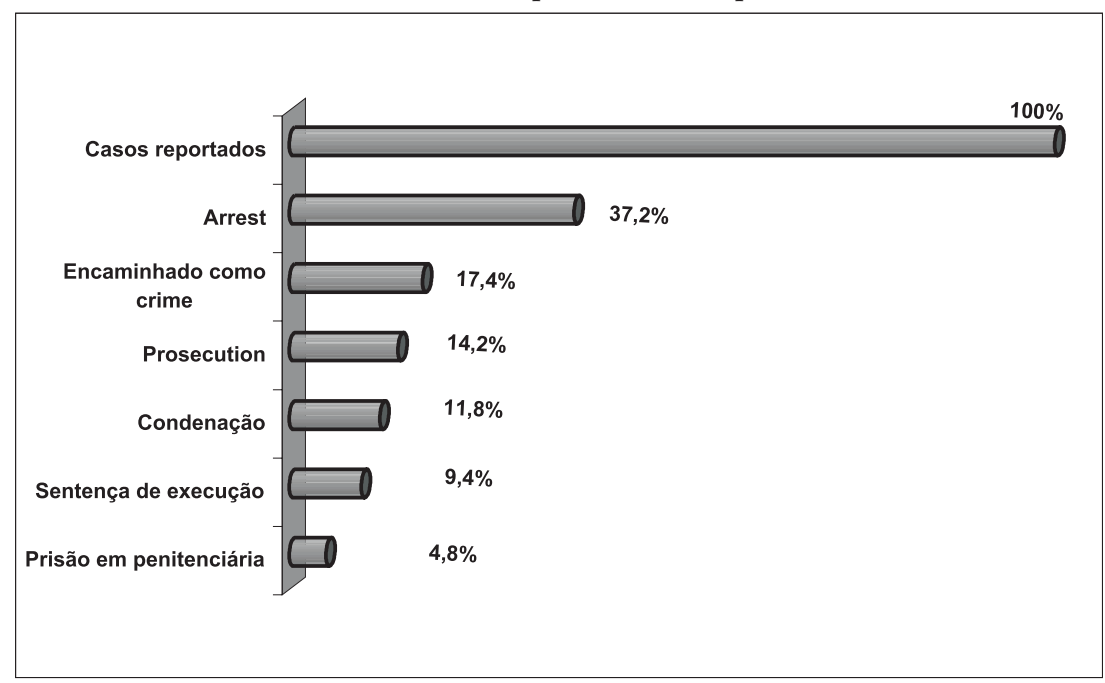

Fonte: LaFree (1989:60, tradução da autora) 
Observa-se que a maior filtragem ocorre na fase policial, com o arquivamento de $62,8 \%$ dos casos iniciais, e, posteriormente, com a nãotransformação em crime de $53,4 \%$ dos casos de arrest. O fluxo revela que, dos casos reportados inicialmente, apenas $11,8 \%$ obtiveram sentença de condenação e somente $4,8 \%$ obtiveram penas mais graves, que resultaram na prisão em penitenciária.

Esta breve comparação da descrição quantitativa das decisões tomadas nestes diferentes sistemas de Justiça Criminal (Brasil e Estados Unidos) para o crime de estupro, embora ainda pouco aprofundada para se pretender o rigor de um estudo comparativo, permite, por ora, algumas constatações. Em primeiro lugar, ela corrobora os muitos estudos sobre a Justiça Criminal que afirmam que o fenômeno do atrito se apresenta de forma bastante acentuada nos crimes de estupro, em que menos de $12 \%$ das queixas iniciais terminam em condenação. Em segundo lugar, aponta a fase policial como aquela em que ocorre o grande processo de seleção e filtragem dos casos.

A comparação da produção quantitativa das decisões nas diferentes fases do fluxo entre os dois países possibilita uma primeira exploração sobre o tratamento dado ao crime de estupro pela Justiça. A seguir, procuro aprofundar essa investigação, comparando os determinantes das decisões da fase policial - porta de entrada no sistema de Justiça - identificada como a mais problemática nos dois estudos. Interessa saber se também os determinantes das decisões da fase policial são os mesmos. Mas, antes, faz-se necessária uma descrição das pessoas implicadas (vítima e agressor) e das características das ocorrências apresentadas nesta fase nas duas pesquisas.

\section{Perfis dos Envolvidos e Características das Ocorrências de Estupro na Fase Policial em Indianápolis}

Os dados referentes às queixas iniciais apresentados no estudo de LaFree (1989) estão exibidos na Tabela 1. Sobre as características das vítimas e dos agressores, estes dados indicam que $65,6 \%$ das vítimas tinham 18 anos ou mais de idade e que $73 \%$ dos agressores tinham mais de 21 anos. Queixas envolvendo vítimas e agressores pretos são as mais representadas $(44,1 \%)$, seguidas daquelas envolvendo vítimas e agressores brancos $(33 \%)$ e vítimas brancas agredidas por pretos $(22,9 \%)$. 
Tabela 1

Características do Estupro e de seu Processamento na Fase Policial em Indianápolis

\begin{tabular}{|c|c|c|c|}
\hline \multirow[t]{2}{*}{ Variável } & \multirow[t]{2}{*}{ Codificação } & \multicolumn{2}{|c|}{ Distribuição } \\
\hline & & $\mathbf{N}$ & $\%$ \\
\hline $\begin{array}{l}\text { Resultados: } \\
\text { Queixa infundada }\end{array}$ & $\begin{array}{l}0=\text { Não } \\
1=\text { Sim }\end{array}$ & $\begin{array}{c}844 \\
60\end{array}$ & $\begin{array}{c}93,4 \\
6,6\end{array}$ \\
\hline Arrest (detenção) & $\begin{array}{l}0=\text { Não } \\
1=\text { Sim }\end{array}$ & $\begin{array}{l}580 \\
324\end{array}$ & $\begin{array}{l}64,2 \\
35,8 \\
\end{array}$ \\
\hline $\begin{array}{l}\text { Felony screening (revisão da } \\
\text { promotoria) }\end{array}$ & $\begin{array}{l}0=\text { Arquivamento } \\
1=\text { Crime (felony) }\end{array}$ & $\begin{array}{l}176 \\
148\end{array}$ & $\begin{array}{l}54,3 \\
45,7\end{array}$ \\
\hline $\begin{array}{l}\text { Características da vítima e } \\
\text { do suspeito: } \\
\text { Composição racial }\end{array}$ & $\begin{array}{l}\text { Vítima e agressor pretos (VP/AP) } \\
\text { Vítima branca e agressor preto } \\
\text { (VB/AP) } \\
\text { Vítima branca e agressor branco } \\
\text { (VB/AB) }\end{array}$ & $\begin{array}{l}383 \\
199 \\
287\end{array}$ & $\begin{array}{l}44,1 \\
22,9 \\
33,0\end{array}$ \\
\hline Idade da vítima & $\begin{array}{l}0=18 \text { anos ou mais } \\
1=17 \text { anos ou menos }\end{array}$ & $\begin{array}{l}594 \\
224\end{array}$ & $\begin{array}{l}65,6 \\
27,0\end{array}$ \\
\hline Idade do suspeito & $\begin{array}{l}0=21 \text { anos ou mais } \\
1=20 \text { anos ou menos }\end{array}$ & $\begin{array}{l}606 \\
224\end{array}$ & $\begin{array}{l}73,0 \\
27,0\end{array}$ \\
\hline $\begin{array}{l}\text { Comportamento da } \\
\text { vítima: } \\
\text { Alegada não-concordância }\end{array}$ & $\begin{array}{l}0=\text { Não } \\
1=\text { Sim }\end{array}$ & $\begin{array}{c}874 \\
31\end{array}$ & $\begin{array}{r}96,6 \\
3,4\end{array}$ \\
\hline Resistência da vítima & $\begin{array}{l}0=\text { Não } \\
1=\text { Resistência física }\end{array}$ & $\begin{array}{l}695 \\
206 \\
\end{array}$ & $\begin{array}{l}77,6 \\
22,3 \\
\end{array}$ \\
\hline $\begin{array}{l}\text { Prontidão em reportar à } \\
\text { polícia }\end{array}$ & $\begin{array}{l}0=\text { Menos de } 1 \text { hora } \\
1=\text { Entre } 1 \text { e } 24 \text { horas } \\
2=\text { Mais de } 24 \text { horas }\end{array}$ & $\begin{array}{c}513 \\
290 \\
60 \\
\end{array}$ & $\begin{array}{c}59,4 \\
33,6 \\
7,0 \\
\end{array}$ \\
\hline $\begin{array}{l}\text { Contexto interpessoal: } \\
\text { Relacionamento entre víti- } \\
\text { ma e agressor }\end{array}$ & $\begin{array}{l}0=\text { Desconhecido } \\
1=\text { Conhecido }\end{array}$ & $\begin{array}{l}435 \\
440\end{array}$ & $\begin{array}{l}49,7 \\
50,3\end{array}$ \\
\hline Local do incidente & $\begin{array}{l}0=\text { Fora de casa } \\
1=\text { Dentro de casa }\end{array}$ & $\begin{array}{l}556 \\
243\end{array}$ & $\begin{array}{l}69,6 \\
30,4\end{array}$ \\
\hline Número de agressores & $\begin{array}{l}0=\mathrm{Um} \\
1=\text { Mais de um }\end{array}$ & $\begin{array}{l}676 \\
228\end{array}$ & $\begin{array}{l}74,8 \\
25,2\end{array}$ \\
\hline $\begin{array}{l}\text { Evidência: } \\
\text { Lesão física }\end{array}$ & $\begin{array}{l}1=\text { Não } \\
2=\text { Pequena, autotratada } \\
3=\text { Hospitalizada }\end{array}$ & $\begin{array}{c}268 \\
596 \\
37 \\
\end{array}$ & $\begin{array}{c}29,7 \\
66,1 \\
4,1 \\
\end{array}$ \\
\hline Testemunha & $\begin{array}{l}0=\text { Não } \\
1=\text { Sim }\end{array}$ & $\begin{array}{l}714 \\
188\end{array}$ & $\begin{array}{l}79,2 \\
20,8\end{array}$ \\
\hline Uso de arma & $\begin{array}{l}0=\text { Não } \\
1=\text { Arma de fogo, faca, outros }\end{array}$ & $\begin{array}{l}599 \\
276 \\
\end{array}$ & $\begin{array}{l}68,4 \\
31,6 \\
\end{array}$ \\
\hline
\end{tabular}

Fonte: LaFree (1989), elaboração da autora. 
Estupros de vítimas pretas por agressores brancos foram excluídos devido ao pequeno número de casos registrados. No que se refere ao contexto interpessoal de relação entre vítima e agressor, os dados informam que os agressores desconhecidos representam 49,7\% dos casos, e os conhecidos, 50,3\%. A maioria das ocorrências deu-se fora de casa $(69,3 \%)$, predominantemente com um único agressor $(74,8 \%)$, sem o uso de arma $(68,4 \%)$ e com lesão física de menor gravidade $(66,1 \%)$. Quanto ao comportamento da vítima, foi alegada não-concordância em 3,4\% dos casos e resistência física em $22,3 \%$ dos casos. Quanto aos resultados, 93,4\% das queixas foram consideradas fundadas, 35,8\% resultaram em detenção (arrest); destas, 45,7\% foram encaminhadas como crime.

\section{Perfis dos Envolvidos e Características das Ocorrências de Estupro na Fase Policial em Campinas}

Os dados referentes à fase policial em Campinas estão apresentados na Tabela $2^{12}$. A seguir, selecionarei algumas variáveis para comparar as distribuições encontradas em ambos os estudos. Começarei com a "composição racial", não sem antes lembrar que, no Brasil, a raça tem sido representada como "cor" ${ }^{\prime 13}$.

Os dados de Campinas indicam que a maior parte das queixas podem ser classificadas como de estupro intra-racial, com um agressor branco acusado de estupro de uma vítima branca (43\%). Entretanto, não são poucas as queixas inter-raciais com vítima branca. Estas representam $27,5 \%$ do total de queixas, sendo $16 \%$ contra um agressor pardo e $11,5 \%$ contra um agressor preto.

Se comparada ao estudo de LaFree (1989), que encontrou uma proporção de vítimas e agressores pretos no total das queixas de $44,1 \%$, a composição vítima e agressor de cor preta encontrada em Campinas é muito baixa, representando apenas 3\% do total das queixas. Tal composição continua baixa mesmo se somarmos estes últimos com as vítimas e agressores pardos, o que irá representar $14 \%$ do total de queixas. A proporção de vítimas pardas que deram queixas contra um agressor branco, no total das queixas, é de $9 \%$. A proporção mais baixa encontrada neste total é, assim como no estudo de LaFree, a da queixa da vítima de cor preta contra agressor de cor branca (1\%). Observa-se que as vítimas nos dados de Campinas são mais jovens do que aquelas apresentadas no estudo americano. Tal diferença certamente se deve ao fato deste autor ter excluído statutory rape de sua análise ${ }^{14}$. 
Tabela 2

Características do Estupro e de seu Processamento na Fase Policial em Campinas

\begin{tabular}{|c|c|c|c|}
\hline \multirow[t]{2}{*}{ Variável } & \multirow[t]{2}{*}{ Codificação } & \multicolumn{2}{|c|}{$\begin{array}{l}\text { Distribui- } \\
\text { ção }\end{array}$} \\
\hline & & $\mathbf{N}$ & $\%$ \\
\hline \multicolumn{4}{|l|}{ Resultados: } \\
\hline Queixas & & 427 & 100 \\
\hline \multirow{2}{*}{$\begin{array}{l}\text { Instauração de in- } \\
\text { quérito }\end{array}$} & $0=$ Não & 283 & 71,6 \\
\hline & $1=\operatorname{Sim}$ & 112 & 28,4 \\
\hline \multicolumn{4}{|c|}{$\begin{array}{l}\text { Características da } \\
\text { vítima e do sus- } \\
\text { peito: }\end{array}$} \\
\hline \multirow[t]{2}{*}{ Idade da vítima } & $0=$ Menor de 14 anos & 102 & 26,5 \\
\hline & $1=14$ anos ou mais & 283 & 73,5 \\
\hline \multirow[t]{3}{*}{ Idade do suspeito } & $1=29$ anos ou menos & 140 & 54,5 \\
\hline & $2=30-44$ anos & 97 & 37,7 \\
\hline & $3=45$ anos ou mais & 20 & 7,8 \\
\hline \multirow[t]{3}{*}{ Cor da vítima } & $1=$ Branca & 264 & 72,5 \\
\hline & $2=$ Parda & 77 & 21,2 \\
\hline & $3=$ Preta & 23 & 6,2 \\
\hline \multirow[t]{3}{*}{ Cor do agressor } & $1=$ Branca & 160 & 53,5 \\
\hline & $2=$ Parda & 81 & 27,1 \\
\hline & $3=$ Preta & 58 & 19,4 \\
\hline \multirow{3}{*}{$\begin{array}{l}\text { Estado civil da ví- } \\
\text { tima }\end{array}$} & $1=$ Casada & 47 & 12,6 \\
\hline & $2=$ Solteira & 300 & 80,4 \\
\hline & $3=$ Outra & 26 & 7,0 \\
\hline \multirow{3}{*}{$\begin{array}{l}\text { Estado civil do } \\
\text { agressor }\end{array}$} & $1=$ Casado & 75 & 36,1 \\
\hline & $2=$ Solteiro & 92 & 44,2 \\
\hline & $3=$ Outro & 41 & 19,7 \\
\hline \multirow{3}{*}{$\begin{array}{l}\text { Contexto inter- } \\
\text { pessoal: } \\
\text { Relacionamento } \\
\text { entre vítima e } \\
\text { agressor }\end{array}$} & & & \\
\hline & $0=$ Desconhecido & 133 & 39,3 \\
\hline & $1=$ Conhecido & 205 & 60,7 \\
\hline
\end{tabular}

(continua) 
Tabela 2

Características do Estupro e de seu Processamento na Fase Policial em Campinas

(continuação)

\begin{tabular}{|c|c|c|c|}
\hline \multirow[t]{2}{*}{ Variável } & \multirow[t]{2}{*}{ Codificação } & \multicolumn{2}{|c|}{$\begin{array}{l}\text { Distribui- } \\
\text { ção }\end{array}$} \\
\hline & & $\mathbf{N}$ & $\%$ \\
\hline \multirow{9}{*}{$\begin{array}{l}\text { Composição raci- } \\
\text { al (vítima e agres- } \\
\text { sor) } \\
\text { (Sem informação } \\
34,4 \% \text { ) }\end{array}$} & $1=$ Vítima preta $/$ Agressor preto $(\mathrm{VP} / \mathrm{AP})$ & 9 & 3,0 \\
\hline & 2 = Vítima preta/Agressor branco $(\mathrm{VP} / \mathrm{AB})$ & 3 & 1,0 \\
\hline & $3=$ Vítima preta / Agressor pardo (VP / APar) & 5 & 1,5 \\
\hline & 4 = Vítima branca / Agressor preto $(\mathrm{VB} / \mathrm{AP})$ & 32 & 11,5 \\
\hline & $5=$ Vítima branca $/$ Agressor branco $(\mathrm{VB} / \mathrm{AB})$ & 120 & 43,0 \\
\hline & 6 = Vítima branca / Agressor pardo (VB/APar) & 44 & 16,0 \\
\hline & 7 = Vítima parda $/$ Agressor preto $(\mathrm{VPar} / \mathrm{AP})$ & 11 & 4,0 \\
\hline & 8 = Vítima parda /Agressor branco (VPar/AB) & 24 & 9,0 \\
\hline & 9 = Vítima parda/Agressor pardo (VPar/APar) & 30 & 11,0 \\
\hline \multirow{2}{*}{$\begin{array}{l}\text { Coincide local do } \\
\text { fato com a resi- } \\
\text { dência da vítima? }\end{array}$} & $0=$ Não & 234 & 63,6 \\
\hline & $1=\operatorname{Sim}$ & 135 & 36,4 \\
\hline \multirow{2}{*}{$\begin{array}{l}\text { Prisão durante a } \\
\text { investigação? }\end{array}$} & $0=$ Não & 87 & 76,1 \\
\hline & $1=\operatorname{Sim}$ & 27 & 23,9 \\
\hline \multirow[t]{2}{*}{ Uso de arma } & $0=$ Não & 184 & 60,9 \\
\hline & $1=$ Arma de fogo, faca ou outro & 118 & 39,1 \\
\hline \multirow{8}{*}{$\begin{array}{l}\text { Solução dada à } \\
\text { queixa }\end{array}$} & 1 = Sem acesso à informação & 111 & 26,0 \\
\hline & $2=$ Arquiva-se por vontade da vítima & 99 & 23,2 \\
\hline & 3 = Arquiva-se por determinação da autoridade & 22 & 5,2 \\
\hline & $4=$ Aguardar em cartório & 38 & 8,9 \\
\hline & $5=$ Arquiva-se, suspeito não-identificado & 81 & 19,0 \\
\hline & $6=$ Representação feita pela vítima & 48 & 11,2 \\
\hline & $7=$ Representação feita pelo Estado & 25 & 5,8 \\
\hline & $8=$ Outros & 3 & 0,7 \\
\hline
\end{tabular}

Fonte: Vargas (2004).

Nota-se, quanto à relação de conhecimento entre vítima e agressor, uma proporção maior nos dados de Campinas de "conhecidos". As classificações deduzidas dos registros de Campinas foram agrupadas inicialmente em "conhecido" e "desconhecido" e, com o intuito de qualificar melhor o grau da relação de conhecimento, foram agrupadas em: "pai", "padrasto", "namorado", "marido", "outro parente", "vizinho", "conhecido", "relação de trabalho" e "outros". A classificação 
"outro parente" engloba tio, avô, irmão, cunhado etc. Já a classificação "conhecido", agrupa aqueles suspeitos que aparecem, deste modo, nos relatos, mas cujo grau de relação com a vítima não é explicitado ${ }^{15}$.

Quando se correlaciona a idade da vítima com a relação entre a desta e a do agressor, verifica-se que $89 \%$ das vítimas de 0 a 8 anos e $84 \%$ das vítimas de 9 a 13 anos deram queixas contra agressores conhecidos. Esta porcentagem para as vítimas de 14 a 19 anos é de 55\%. Desta faixa etária em diante (com exceção das faixas etárias dos 35 aos 39 anos e dos 45 aos 49 anos), a proporção de agressores desconhecidos sobressai-se à dos conhecidos.

Vítimas muito jovens apresentam queixas principalmente contra agressores íntimos, geralmente parentes: pai $(47 \%)$, padrasto $(6,5 \%)$, outro parente $(27 \%)$ e conhecidos: vizinho $(6,5 \%)$, conhecido $(6,5 \%)$, outro $(6,5 \%)$. Na faixa seguinte, dos 9 aos 13 anos, há queixas contra os parentes: pai (25\%), padrasto (10\%) e outro parente $(12,5 \%)$, mas também contra agressores só conhecidos $(19,5 \%)$, namorados (21\%), vizinhos $(8 \%)$, relação de trabalho $(4 \%)$. Queixas contra conhecidos acentuam-se na faixa seguinte (dos 14 aos 19 anos), diminuindo a freqüência de parentes: pai (19\%), padrasto $(4 \%)$, outro parente $(15 \%)$ e aumentando a de namorado (11\%) e conhecido (35\%), além de vizinho $(4 \%)$ e relação de trabalho (7\%). Na faixa dos 20 aos 29 anos, mais da metade das queixas são contra agressores apenas conhecidos. Na faixa dos 30 aos 39 anos, destacam-se os maridos e os apenas conhecidos. Dos 50 anos em diante, predominam, nos poucos registros, os agressores desconhecidos das vítimas.

Estes resultados aproximam-se daqueles encontrados em estudos mais recentes e indicam que o estupro não é uma categoria homogênea, apontando para a existência de mudanças quanto à natureza das queixas feitas na polícia, agora apresentando um maior número de queixas contra agressores conhecidos e íntimos (Estrich, 1987; Harris e Grace, $1999)^{16}$.

Finalmente, observa-se, tanto no estudo de LaFree quanto nos dados de Campinas, que, na maioria dos casos (mais de 60\%), não foi relatado o uso de arma; e, embora não seja possível comparar a proporção dos casos no que diz respeito às variáveis "vontade da vítima de processar" e "não identificação do suspeito", verifica-se, no estudo de Campinas, que estas são duas importantes características deste crime, no 
que se refere à decisão da polícia de dar (ou não) prosseguimento ao caso.

\section{DETERMINANTES DAS DECISÕES DA FASE POLICIAL PARA O CRIME DE ESTUPRO EM INDIANÁPOLIS}

Nesta seção, compararei os determinantes das decisões das vítimas e operadores para o prosseguimento da ação judicial encontradas nas duas pesquisas. A Tabela 3 apresenta o resultado da análise de regressão múltipla, realizada por LaFree (1989), e mostra os maiores preditores para cada uma das três decisões identificadas por este autor, na fase policial, ordenados de acordo com os seus coeficientes de regressão estandardizados. Os maiores determinantes da decisão de se considerar a queixa de estupro fundada são a identificação do suspeito e a vontade da vítima de processar o autor.

Tabela 3

Melhores Preditores para Investigação, Acusação e Encaminhamento como Crime para o Estupro em Indianápolis

\begin{tabular}{|c|c|c|c|c|c|}
\hline \multicolumn{2}{|c|}{ Investigação (arrest) $\mathrm{N}=769$} & \multicolumn{2}{|c|}{ Acusação $($ charge) $\mathrm{N}=324$} & \multicolumn{2}{|c|}{$\begin{array}{c}\text { Encaminhar como Crime } \\
(\text { felony filed }) \mathrm{N}=324\end{array}$} \\
\hline Variável & Beta & Variável & Beta & Variável & Beta \\
\hline $\begin{array}{l}\text { Identificação do sus- } \\
\text { peito }\end{array}$ & 0,541 & Tipo de ofensa & 0,378 & $\begin{array}{l}\text { Seriedade da ofen- } \\
\text { sa }\end{array}$ & 0,206 \\
\hline Vítima quer processar & 0,137 & Arma & 0,255 & $\begin{array}{l}\text { Número de ofen- } \\
\text { sores }\end{array}$ & $-0,167$ \\
\hline $\begin{array}{l}\text { Não-conformidade da } \\
\text { vítima }\end{array}$ & $-0,056$ & Idade da vítima & 0,213 & Idade da vítima & $-1,64$ \\
\hline Prontidão em reportar & $-0,025$ & $\begin{array}{l}\text { Prontidão em repor- } \\
\text { tar }\end{array}$ & $-0,185$ & $\begin{array}{l}\text { Vítima quer pro- } \\
\text { cessar }\end{array}$ & 0,093 \\
\hline $\begin{array}{l}\text { Relação vítima/sus- } \\
\text { peito }\end{array}$ & 0,024 & $\begin{array}{l}\text { Suspeito negro/víti- } \\
\text { ma branca }\end{array}$ & 0,134 & & \\
\hline Arma & 0,023 & $\begin{array}{l}\text { Vítima quer proces- } \\
\text { sar }\end{array}$ & 0,081 & & \\
\hline
\end{tabular}

Fonte: LaFree (1989:75, tradução da autora).

Influencia a decisão de não considerar a queixa fundada a não-conformidade da vítima a padrões de comportamento estabelecidos. Na decisão de acusar (charge), o tipo de ofensa, o uso de arma e a idade da vítima aparecem como determinantes importantes. LaFree (idem) verificou que também influencia esta decisão o fato de o agressor ser preto e 
a vítima, branca. Na decisão de encaminhar o caso como crime sério ( $f e l-$ ony), os principais determinantes são a seriedade da ofensa e a vontade da vítima de testemunhar.

Os principais determinantes das decisões da fase policial foram interpretados por LaFree (1981) como fatores considerados relevantes pelos operadores para dar prosseguimento ao processamento dos casos na Justiça e classificados como predominantemente legais, em oposição, portanto, à orientação dos estudos anteriores, que enfatizavam as atitudes discriminatórias dos policiais em relação às vítimas de estupro.

Contudo, atitudes discriminatórias da polícia em relação a certo tipo de vítimas ou de agressores (fatores classificados como extralegais) foram identificadas na decisão de não considerar a queixa fundada, quando a conduta da vítima não se apresenta em conformidade com os padrões estabelecidos, bem como na decisão de considerar a queixa fundada, quando um agressor negro é suspeito de estuprar uma vítima branca.

\section{DETERMINANTES DAS DECISÕES DA JUSTIÇA CRIMINAL PARA O CRIME DE ESTUPRO: SUBMETENDO O DIREITO À ANÁLISE}

A interpretação de LaFree (1981) dos determinantes encontrados na fase policial nos suscita uma reflexão sobre as variáveis por ele trabalhadas, para além da dicotomia legal/extralegal usualmente utilizada. Tal dicotomia obscurece o fato de que discriminações de raça, de gênero e de idade podem estar embutidas nos critérios legais normalmente considerados legítimos e neutros (Pires e Landreville, 1985). A discussão do conteúdo social das variáveis legais, tal como o da variável "prisão durante o processo", buscando identificar como ela pode assumir um caráter extralegal, quando revela tratamento discriminatório dado a certos réus, deverá ser trabalhada em outro momento. Por ora, quero chamar a atenção para o fato de que variáveis consideradas extralegais, tal como a "idade da vítima", podem também assumir um caráter legal em razão da aplicação de certas prescrições jurídicas. Com isto, pretendo averiguar o aspecto legal prescritivo delimitador das decisões contido nesta variável, bem como na variável "vontade da vítima de processar", aspecto este não explorado por LaFree em particular, nem nos estudos sobre o tratamento dado ao estupro na Justiça Criminal em geral. Portanto, passo agora a descrever as variáveis "vontade da vítima de processar" e "idade da vítima". 


\section{a) A variável "vontade da vítima de processar"}

Já foi dito que a ação penal em caso de estupro é privada. Em determinadas circunstâncias, o Ministério Público pode promover a ação, tornando-a pública mediante representação. Para tanto, ele precisa ter a manifestação ou autorização da vítima. São os casos em que a vítima ou seus pais não podem pagar as custas do processo sem privar-se de recursos indispensáveis à manutenção própria ou da família. Em casos em que o suspeito é pai, padrasto ou tutor da vítima, a ação penal é pública incondicionada, isto é, o Ministério Público deve acionar a Justiça independentemente da vontade da vítima (art. 225, § 1으, II do Código Penal). A ação penal também é pública no caso de haver lesão corporal grave, gravíssima, ou morte da vítima ${ }^{17}$.

A vontade da vítima de processar tem sido interpretada como uma decisão instrumental (Kerstetter, 1990), legal (LaFree, 1981), ou como uma decisão que envolve a interação da vítima com os operadores, sendo, muitas vezes, marcada por atitudes discriminatórias dos policiais ou dos promotores (LaFree, 1989; Frohmann, 1991; Bryden e Lengnick, 1997). No banco de dados, esta variável aparece como uma das categorias da variável "solução dada à queixa", quais sejam: 1 = "sem acesso à informação"; 2 = "arquiva-se por vontade da vítima"; 3 = "arquiva-se por determinação da autoridade"; 4 = "aguardar em cartório outro procedimento"; $5=$ "arquiva-se suspeito não-identificado"; $6=$ "representação feita pela vítima"; 7 = "representação feita pelo Estado"; 8 = "outros". Vê-se, pois, que considerei as outras hipóteses de ação neste tipo de crime para definir esta variável e que a não-identificação do suspeito, categoria considerada importante no estudo de LaFree (1989), também está aqui representada ${ }^{18}$.

\section{b) A variável "idade da vítima"}

O Código Penal prevê que se presuma a violência da ocorrência quando a vítima não é maior de 14 anos, é débil mental e o agente conhecia este fato, ou por qualquer outra razão (embriaguez, inconsciência, enfermidade) que a impediu de resistir ao ato (art. 224 do Código Penal) uma maneira de procurar proteger as vítimas que apresentam menor possibilidade de defesa. Em relação à presunção da violência em razão da idade, o Código, promulgado em 1940, apóia-se na presunção de que até esta idade a vítima é desconhecedora dos assuntos sexuais, de modo que o seu consentimento não deve ser considerado válido ${ }^{19}$. 
Vê-se, pois, que a variável "idade da vítima" agrega um conteúdo jurídico que delimita a atividade de seleção e de interpretação dos casos exercida pelos operadores. Suponho, e procurarei verificar ao longo deste artigo, que o critério jurídico que define ser a violência presumida para vítimas menores de 14 anos funciona como fator de progressão destas no fluxo, uma espécie de discriminação positiva, pois, para estes casos, dispensam-se as provas de violência e do não-consentimento. Assim, a variável "idade da vítima" foi categorizada como 0 = "até 14 anos" e 1 = "com 14 anos ou mais".

\section{DETERMINANTES DAS DECISÕES DA FASE POLICIAL PARA O CRIME DE ESTUPRO EM CAMPINAS}

As Tabelas 4 e 5 apresentam os dois modelos resultantes da regressão logística que considera a categorização dicotômica da decisão da polícia com respeito ao inquérito: indiciamento do suspeito versus não-indiciamento. O que se busca verificar, por meio desta técnica, são os fatores que afetam a probabilidade de essas decisões ocorrerem.

Tabela 4

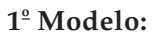

Regressão Logística para a Instauração de Inquérito de Estupro em Campinas

\begin{tabular}{l|r|r|r|r|r|r}
\hline Variável & \multicolumn{1}{|c|}{ B } & S.E. & Wald & Df & Sig. & EXP(B) \\
\hline Solução & & & 82,857 & 7 & 0,000 & \\
Arquiva-se por vontade da vítima & $-3,481$ & 0,654 & 28,318 & 1 & 0,000 & 0,031 \\
Arquiva-se por determinação da autoridade & $-9,376$ & 21,760 & 0,186 & 1 & 0,667 & 0,000 \\
Aguardar em cartório & $-3,562$ & 1,061 & 11,261 & 1 & 0,000 & 0,028 \\
Suspeito não-identificado & $-3,343$ & 0,764 & 19,165 & 1 & 0,000 & 0,035 \\
Representação feita pela vítima & 4,016 & 1,046 & 14,741 & 1 & 0,000 & 55,477 \\
Representação feita pelo Estado & 2,800 & 1,065 & 6,912 & 1 & 0,009 & 16,437 \\
Outro & $-0,268$ & 1,257 & 0,045 & 1 & 0,831 & 0,765 \\
Idade da vítima & $-1,280$ & 0,467 & 7,516 & 1 & 0,006 & 0,278 \\
Constante & 0,854 & 0,425 & 4,037 & 1 & 0,045 & 2,350 \\
\hline
\end{tabular}

Fonte: Dados de BOs 1988-1992, DDM de Campinas.

$\mathrm{P}<0,05-2 \log \mathrm{L}=162,334$.

Pseudo $\mathrm{R}^{2}=54 \%$ (mede o quanto de variação na variável resposta é explicada pelo modelo). $\mathrm{EXP}(\mathrm{B})=$ razão de risco na classe.

O primeiro modelo mostra que os principais determinantes da decisão com respeito ao indiciamento do suspeito em inquérito para as queixas de estupro registradas em Campinas são a vítima querer processar e a 
não-identificação do suspeito. A representação feita pela vítima é o fator que mais determina o indiciamento do suspeito. $\mathrm{O}$ arquivamento por vontade desta e a não-identificação do suspeito são os fatores que mais determinam a não-instauração do inquérito. Estes resultados coadunam-se com aqueles encontrados no estudo de LaFree (1989) e também com o meu estudo anterior (Vargas, 2000). Entretanto, a presente análise permite quantificá-los melhor. Ela nos mostra, por exemplo, que, quando a vítima decide processar o agressor, a chance de instauração do inquérito aumenta 55 vezes, comprovando que, nesses crimes, é basicamente a vítima quem abre a porta de entrada do sistema. Já a chance de não-instauração do inquérito aumenta 32 vezes quando a vítima não quer processar o agressor e 28 vezes quando não foi possível identificar o suspeito.

Estes resultados mostram, de um lado, ser plausível a minha hipótese da importância das regras legais como delimitadoras de comportamentos e ações dos operadores do sistema de Justiça, a qual pode ser verificada em relação à decisão da vítima de processar o agressor. De tal forma que a regra da ação penal privada se constitui como condição de instauração de inquérito e, por isto, deve ser considerada parte integrante da variável dependente (daí a necessidade de constituição de um segundo modelo sem considerar a variável "solução"). De outro lado, os resultados também reforçam um aspecto importante, já por mim explorado, qual seja, o problema da investigação da autoria neste tipo de crime, que, nas DDMs em geral, assume um caráter dramático (idem). Antes de discutir esta última afirmação, quero explorar melhor a questão das regras e de sua aplicação.

Vimos que a ação privada pode se tornar pública, mediante representação da vítima ou de seu responsável legal, quando esta alega não poder arcar com as custas do processo. Na atividade cotidiana dos operadores da Justiça, esta prescrição tornou-se uma prática. As queixosas, cujos casos ensejam a instauração de inquérito e que querem acionar a Justiça, são orientadas a assinar um termo de representação, alegando não poder pagar pelo processo e pedindo a ação do Estado. O conflito, que era privado, torna-se, então, público, e a Justiça Criminal é acionada para resolvê-lo. Portanto, como afirmado anteriormente, é a decisão da vítima que aciona o sistema neste tipo de crime. Trata-se de uma regra definida pelo direito, prevista em código, que delimita o comportamento dos queixosos e o trabalho dos operadores e, a meu ver, explica, em parte, como se dá a seleção dos casos nesta primeira fase do fluxo. 
Quando a vítima ou seus responsáveis legais não se manifestam oficialmente por queixa privada (queixa-crime) ou não requerem, por meio de representação, que o Ministério Público denuncie o acusado, o caso é arquivado.

Os resultados do segundo modelo da regressão logística, que não comporta o efeito da variável "solução", mostram que a vítima ter até 14 anos, ser conhecida do réu e a ocorrência ter sido em sua residência aumentam as chances de instauração do inquérito. Vimos, anteriormente, que vítimas de até 14 anos (89\% das vítimas de 0 a 8 anos e $84 \%$ das vítimas de 9 a 13 anos) deram queixas contra agressores conhecidos. A análise mostra agora que as chances de instauração de inquérito para estes casos são maiores do que para as vítimas de 14 anos ou mais, faixa na qual se encontra uma proporção maior de vítimas que acusam de estupro suspeitos desconhecidos.

Tabela 5

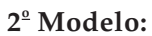

Regressão Logística para a Instauração de Inquérito de Estupro em Campinas

\begin{tabular}{l|c|c|r|c|c|c}
\hline Variável & B & S.E. & Wald & Df & Sig. & EXP(B) \\
\hline Idade da vítima & $-0,913$ & 0,319 & 8,178 & 1 & 0,004 & 0,401 \\
Relação & 1,465 & 0,416 & 12,407 & 1 & 0,000 & 4,328 \\
Residência & 0,908 & 0,306 & 8,803 & 1 & 0,003 & 2,479 \\
Constante & $-2,087$ & 0,469 & 19,821 & 1 & 0,000 & 0,124 \\
\hline
\end{tabular}

Fonte: Dados de BOs 1988-1992, DDM de Campinas.

$\mathrm{P}<0,05-2 \log \mathrm{L}=249,104$.

Pseudo $\mathrm{R}^{2}=15,2 \%$.

$\mathrm{EXP}(\mathrm{B})=$ razão de risco na classe.

A explicação usualmente dada à influência da idade no tratamento penal do estupro centra-se, de um lado, em uma maior reação dos operadores ao estupro de vítimas muito jovens e uma grande dificuldade em reconhecer a agressão, quando a vítima é adolescente ou adulta (especialmente quando vítima e agressor se conhecem) e, de outro, no cálculo instrumental feito por estes da probabilidade de o caso prosseguir no sistema, incentivando ou não a queixosa em sua decisão de acioná-lo (Spohn, Beichner e Davis-Frenzel, 2001).

Quero sugerir como explicação adicional o fato de se presumir a violência quando a vítima tem até 14 anos. A presunção de violência para a vítima de até 14 anos facilita a constituição de evidências pelos policiais (não sendo preciso provar o não-consentimento e a violência) e, 
por outro lado, evidencia a dificuldade encontrada pela polícia para constituir provas de não-consentimento para as vítimas de 14 anos ou mais, ainda nesta fase do fluxo.

Mas a idade da vítima também influencia a não-instauração do inquérito por uma outra razão. A classe "14 anos ou mais" é a mais representada na não-instauração do inquérito policial, quando a solução é a "não-identificação do suspeito", reforçando os achados anteriores a respeito da relação entre a idade da vítima e a relação de conhecimento desta com o agressor. No estudo anterior (Vargas, 2000), a pesquisa de campo permitiu observar que, nas situações que envolvem suspeitos desconhecidos da vítima, é comum que estes não venham a ser identificados, uma vez que a prática das policiais da DDM (que se enquadra no comportamento das policiais das DDMs em geral) é, na maioria dos casos, não proceder à investigação. Assim, a análise dos dados de Campinas revela que um fator de natureza organizacional, possivelmente característico da realidade das delegacias especializadas no Brasil (e talvez não só delas), que afeta negativamente a apreensão do crime de estupro pela Justiça Criminal é a ausência de investigação ${ }^{20}$.

Os casos que necessitam de menos investigação são justamente aqueles em que vítimas e agressores se conhecem e, não poucas vezes, trata-se de familiares que habitam a mesma residência. Nestes casos, é mais fácil para as policiais localizar os envolvidos e as testemunhas, condição que, na prática, se revela essencial para dar início à instauração do inquérito policial.

\section{CONSIDERAÇÕES FINAIS}

A dificuldade de passagem da queixa à constituição jurídica do estupro, bem como a baixa proporção de condenação em relação aos casos iniciais apresentam-se como regularidades na resposta que a Justiça Criminal brasileira e a americana oferecem ao crime de estupro.

Atribuí a uma regra de incriminação e de decisão - a que estabelece as hipóteses da ação penal em crime de estupro - boa parte da explicação do atrito, isto é, do arquivamento dos casos, particularmente acentuado nos dois países. E sugeri que tal regra, assim como a regra de presunção da violência, desempenha um papel importante no processamento do estupro na Justiça Criminal brasileira. Busquei empiricamente demonstrar a tese da importância das regras legais como delimitadoras de comportamentos, especialmente, com a análise da variá- 
vel referente à decisão da vítima de processar o agressor. Tal variável foi de tal maneira determinante da decisão de instauração do inquérito policial que precisou ser considerada como parte integrante desta variável independente. O mesmo não ocorreu com a variável "vontade da vítima de processar", enfatizada por LaFree como variável legal e identificada, apenas, como um importante preditor das decisões de dar prosseguimento ao processamento na Justiça. Quanto à regra da presunção da violência, estudos mais aprofundados sobre a fase judicial no Brasil e também sobre a jurisprudência com respeito ao estupro são necessários para investigar como esta tem fundamentado as decisões nesta fase.

Por ora, pode-se pensar que o papel desempenhado pelas regras legais no processamento judicial do crime de estupro poderia ser um indicador de que reformas na legislação com respeito a este crime podem contribuir substantivamente para mudar o modo como ele vem sendo processado no Brasil ${ }^{21}$. Estudos norte-americanos mostraram que, naquele país, o impacto das reformas feitas na legislação tem sido bem menor do que o esperado (Berger, Searles e Neuman, 1988). É provável, mas não é certo, que reformas no mesmo sentido consigam surtir mais efeito no Brasil, tendo em vista a importância assumida pelas regras de incriminação e de procedimento no nosso sistema de direito, em comparação com o sistema americano.

(Recebido para publicação em janeiro de 2007) (Versão definitiva em agosto de 2007) 


\section{NOTAS}

1. O estupro é enquadrado no artigo 213 do Código Penal brasileiro como "constranger mulher à conjunção carnal mediante violência ou grave ameaça: Pena - reclusão de seis a dez anos". A Common Law define rape como penetração sexual feita por um homem a uma mulher, que não seja sua esposa, com o uso da força e sem seu consentimento. Como resultado dos movimentos feministas, a maioria dos estados americanos introduziu algum tipo de reforma na legislação (Berger, Searles e Neuman, 1988).

2. A este respeito ver Bryden e Lengnick (1997), que fizeram uma revisão sobre os estudos americanos que trataram do estupro na Justiça Criminal, e também Vargas (2004).

3. Segundo estes autores, a recusa em submeter o direito à análise encontra-se tradicionalmente presente nos estudos sobre decisão.

4. Segundo este autor, boa parte da criminologia produzida até então tem manifestado um desinteresse pelo papel do direito na constituição do crime.

5. Ao analisar o tratamento dado aos crimes sexuais em Campinas, pude observar, por exemplo, que em situações em que não ocorre a prisão do suspeito, a polícia, em geral, age sozinha e de forma independente até a instauração do inquérito. Após a instauração deste, o Ministério Público passa a ter acesso aos autos e a exercer um controle formal sobre o inquérito, ainda que, na grande maioria das vezes, apenas via papel.

6. Em sua revisão dos estudos realizados sobre o tratamento dado ao estupro pela Justiça Criminal americana, Bryden e Lengnick (1997) mostram que o atrito, isto é, as perdas ou arquivamento dos casos que acontecem em cada fase decisória, é bastante enfatizado e que boa parte dos estudos o atribui à sistemática discriminação do estupro entre conhecidos pelos operadores do sistema. Ainda segundo estes autores, estudos mais recentes buscaram comparar os padrões de atrito do estupro com aqueles observados em outros crimes e concluíram, primeiro, que se poucos estupros resultam em acusação e condenação, isto também ocorre para a maioria dos outros crimes, exceto para o homicídio, e segundo, que a diferença nos casos de atrito de crimes cometidos por estranhos e conhecidos não é específica ao crime de estupro, sendo também observada em outros crimes.

7. Lévy (1987) faz uma revisão detalhada das pesquisas que trataram do modo de apreensão dos casos pelo Sistema de Justiça Criminal, especialmente pela polícia, porta de entrada do sistema.

8. A este respeito ver Fundação Seade (2001).

9. Vale registrar o estudo sobre violência doméstica física e sexual, com recorte nacional, realizado por Saffioti (2002), baseado em boletins de ocorrência (BOs) e seus desdobramentos até a sentença.

10. Em 1985, a partir da iniciativa de um grupo de mulheres, do Conselho Estadual da Condição Feminina e do governo do Estado de São Paulo, foi criada na capital paulista a primeira delegacia voltada ao atendimento de mulheres. O seu objetivo era investigar e instaurar inquéritos de casos de violência contra a mulher sem que fossem tomadas atitudes discriminatórias contra as vítimas. 


\section{Joana Domingues Vargas}

11. Falta a descrição do desfecho de um caso, não fornecida pelo autor. Ver LaFree (1989:59, 60).

12. As análise e crítica dos dados dos BOs foram desenvolvidas anteriormente (Vargas, 2000). Foram identificadas diversas lacunas nos registros, e a principal delas se deve à ausência de dados sobre o agressor.

13. Em trabalho anterior (Vargas, 1999) enfatizei os problemas da variável cor, tanto para a vítima quanto para o agressor. Em geral, esta informação é fornecida pela vítima, e sua categorização é feita na interação com a policial, ou definida por esta.

14. O statutory rape equivale, na legislação brasileira, ao estupro com violência presumida. A exclusão deste tipo de estupro da análise de LaFree limitará consideravelmente, conforme veremos mais à frente, a comparação entre os dois estudos.

15. Além de um índice razoável de ausência de informação para estas variáveis (25\%), é também necessário considerar que esta ausência ou presença de informação não é distribuída na mesma proporção para cada categoria.

16. Uma revisão dos estudos sobre o tratamento dado ao estupro pela Justiça Criminal mostra que houve uma série de mudanças em relação à natureza das queixas e em relação ao modo dos pesquisadores classificá-las e interpretá-las. A este respeito, ver Vargas (2004).

17. Estes casos não são contemplados neste estudo porque são encaminhados para delegacias que investigam homicídios.

18. É bom lembrar que a variável "solução" foi construída a partir dos procedimentos anotados pela autoridade policial nos BOs e que, por estes não serem sempre manifestos, ou por haver uma série de situações que a própria polícia considerou indefinidas, foi encontrada uma alta porcentagem de BOs sem referência à solução dada ao caso, sendo esta informação também codificada.

19. Há, atualmente, bastante polêmica na doutrina e na jurisprudência em relação a este preceito. O entendimento que ora prevalece é o de que a presunção não é absoluta, mas relativa, e que deve ser avaliada em cada caso, muito embora este entendimento, nas decisões absolutórias, seja, muitas vezes, justificado pelo comportamento da vítima e não pelo seu consentimento ao ato (Eluf, 1999).

20. A respeito da ausência de investigação nas delegacias especializadas no atendimento ou de defesa da mulher, ver o relatório da America's Watch (1992). A respeito do baixo percentual de elucidação policial e da complexidade deste trabalho no caso do crime de homicídio, especialmente daquele relacionado ao tráfico de drogas, ver Miranda (2006).

21. Vale destacar, dentre estas propostas de mudanças, a ação penal pública para vítimas menores, a fusão do crime de estupro com o de atentado violento ao pudor, a ampliação da definição da relação sexual, com a inclusão do coito anal e oral, bem como mudanças referentes ao modo como devem ser conseguidos os elementos da prova do não-consentimento. 


\section{REFERÊNCIAS BIBLIOGRÁFICAS}

AMERICA'S WATCH. (1992), Injustiça Criminal x A Violência Contra a Mulher. Rio de Janeiro, Relatório de pesquisa da Human Rights Watch.

AZEVEDO, M. A. e GUERRA, V. N. A. (1988), Pele de Asno Não é Só História: Um Estudo sobre a Vitimização Sexual de Crianças e Adolescentes em Família. São Paulo, Roca.

BERGER, J., SEARLES, P. e NEUMAN, W. (1988), “The Dimension of Rape Reform Legislation". Law \& Society Review, vol. 22, no 2, pp. 329-357.

BRYDEN, D. P. e LENGNICK, S. (1997), "Rape in the Criminal Justice System". Journal of Criminal Law and Criminology, vol. 87, no 4.

CÓDIGO DE PROCESSO PENAL ANOTADO. (1986), Org. Damásio E. de Jesus. São Paulo, Saraiva.

CÓDIGO PENAL E SUA INTERPRETAÇÃO JURISPRUDENCIAL. (1987), São Paulo, Editora Revista dos Tribunais.

COELHO, E. C. (1986), “A Administração da Justiça Criminal no Rio de Janeiro: 1942-1967". DADOS, vol. 29, no 1, pp. 61-81.

CORRÊA, M. (1983), Morte em Família. Rio de Janeiro, Graal.

ELUF, L. N. (1999), Crimes contra os Costumes e Assédio Sexual. Doutrina e Jurisprudência. São Paulo, Editora Jurídica Brasileira Ltda.

ESTRICH, S. (1987), Real Rape. Harvard, Harvard University Press.

FEIGUIN, D., BORDINI, E., MEDRADO, M. A. e PATERNOSTER, M. A. E. (1987), Um Retrato da Violência contra a Mulher - 2.038 Boletins de Ocorrências". São Paulo, Fundação SEADE.

FROHMANN, Lisa. (1991), “'Discrediting Victims' Allegations of Sexual Assault: Prosecutorial Accounts of Case Rejections". Social Problems, vol. 38, no 2, pp. 213-226.

FUNDAÇÃO JOÃO PINHEIRO. (1987), Indicadores Sociais de Criminalidade. Belo Horizonte, relatório de pesquisa, Fundação João Pinheiro.

FUNDAÇÃO SISTEMA ESTADUAL DE ANÁLISE DE DADOS - SEADE. (2001), Consolidação de um Sistema Estadual de Análise e Produção de Dados e Constituição de um Modelo de Tratamento de Informações que Subsidie Políticas Públicas em Justiça e Segurança, em Especial o Centro de Análise Criminal da SSP de São Paulo. São Paulo, relatório parcial de pesquisa da Fundação Seade.

HARRIS, J. e GRACE, S. (1999), A Question of Evidence? Investigating and Prosecuting Rape in the 1990s. London, Home Office.

KANT DE LIMA, R. (1997), "Polícia e Exclusão na Cultura Judiciária”. Tempo Social, vol. 9, no 1, pp. 169-184.

KERSTETTER, W. A. (1990), "Police and Prosecutorial Response to Sexual Assault against Women". The Journal of Criminal Law \& Criminology, vol. 81, no2, pp. 267-313.

LaFREE, G. D. (1981), “Official Reactions to Social Problems: Police Decisions in Sexual Assault Cases". Social Problems, vol. 28, pp. 582-594. 
. (1989), Rape and Criminal Justice: The Social Construction of Sexual Assault. Belmont, Wadsworth Publishing Company.

LÉVY, R. (1987), Du Suspect au Coupable: Le Travail de la Police Judiciaire. Genebra, Editions Médecine et Hygiène.

MIRANDA, A. P. M. (coord.). (2006), “Avaliação do Trabalho Policial nos Registros de Ocorrências e nos Inquéritos Referentes a Homicídios Dolosos Consumados em Áreas de Delegacias Legais". Concursos Nacionais de Pesquisas Aplicadas em Justiça Criminal e Segurança Pública, disponível em http://www.mj.gov.br/senasp/ pesquisas_aplicadas/anpocs/concurso_projetos.htm.

PIRES, A. P. e LANDREVILLE, P. (1985), “Les Recherches sur les Sentences et le Culte de la Loi”. L'Année Sociologique, vol. 35, pp. 83-113.

PIMENTEL, S., SCHRITZMEYER, A. L. e PANDJIARJIAN, V. (1998), Estupro: Crime ou "Cortesia"? Abordagem Jurídica de Gênero. Porto Alegre, Sérgio Antônio Fabris Editor.

ROBERT, P. (1991), “Sociologie et Création de la Loi Pénale”, in P. Robert (ed.), La Création de la Loi et ses Acteurs: L'Example du Droit Pénal. Onãti, Onãti International Institute for the Sociology of Law, pp. 207-215.

SAFFIOTI, H. I. B. (1994), A Vida por um Fio: A Violência contra Crianças e Adolescentes no Brasil Contemporâneo. Trabalho apresentado no XVIII Encontro Anual da Associação Nacional de Pós-Graduação e Pesquisa em Ciências Sociais - Anpocs, Caxambu, 23-27 de novembro.

. (2002), "Violência Doméstica: Questão de Polícia e Sociedade", in M. Corrêa (org.), Gênero e Cidadania. Campinas, PAGU/Núcleo de Estudos de Gênero UNICAMP.

SOARES, B. M. (1996), “Delegacia de Atendimento à Mulher: Questão de Gênero, Número e Grau", in L. E. Soares (org.), Violência e Política no Rio de Janeiro. Rio de Janeiro, Relume Dumará, pp. 107-125.

SPOHN, C., BEICHNER, D. e DAVIS-FRENZEL, E. (2001), "Prosecutorial Justifications for Sexual Assault Case Rejection: Guarding the 'Gateway to Justice'”. Social Problems, vol. 48, no 2, pp. 206-235.

VARGAS, J. D. (1999), “Indivíduos sob Suspeita: A Cor dos Acusados do Estupro no Fluxo da Justiça Criminal”. DADOS, vol. 42, no 4, pp. 729-760.

. (2000), Crimes Sexuais e Sistema de Justiça. São Paulo, Instituto Brasileiro de Ciências Criminais.

. (2004), Estupro: Que Justiça? Fluxo do Funcionamento e Análise do Tempo da Justiça Criminal para o Crime de Estupro. Tese de doutorado, IUPERJ, Rio de Janeiro. Disponível em http: / / www.crisp.ufmg.br. 


\section{ABSTRACT \\ Comparative Analysis of Court Processing of Rape Cases}

The current article is intended to demonstrate the advantages of prioritizing an analysis of court caseload processing for a given type of crime and proceeding to a comparison of the results obtained from empirical studies in different countries. The article draws on a study I performed on rape cases tried by the court system in Campinas, São Paulo State, and the study by Gary LaFree on rape cases in the United States, based on data in Indianapolis, Indiana. The comparative analysis of determinants of victims' and law enforcement agencies' decisions concerning the pursuit of legal action proved to be productive, even when comparing two different systems of justice. This allowed greater knowledge of how the Brazilian criminal justice system operates, both in its capacity to identify, try, and punish sex offenders, and in terms of the importance it ascribes to formal legal rules in trying rape cases, in comparison to the American criminal justice system.

Key words: rape; sexual assault; comparative criminal justice; comparative law; criminal justice caseload

\section{RÉSUMÉ}

Analyse Comparée de la Marche du Système de Justice Concernant le Crime de Viol

Dans cet article, on cherche à montrer les avantages d'utiliser l'analyse de la marche de la production décisionnelle lorsqu'il s'agit de l'étude d'un crime donné ainsi que de comparer les résultats obtenus dans les recherches empiriques menées dans divers pays. On part donc ici de l'étude effectué sur la marche de la Justice Pénale concernant le crime de viol à Campinas (Brésil) ainsi que de l'étude de Gary LaFree sur la façon dont la Justice Pénale nord-américaine considère le viol, d'après des données obtenues à Indianopolis (USA). La comparaison entre les facteurs déterminant les décisions des victimes et les facteurs les opérant dans la poursuite de l'action judiciaire a fourni de bons résultats, malgré les différences entre ces deux systèmes. Elle a permis de mieux connaître le fonctionnement de la Justice Pénale brésilienne autant en ce qui concerne ses possibilités d'identifier, d'étudier et de punir les agressions sexuelles, que dans l'importance qu'elle attribue aux règles légales établies dans les procés de viol, par rapport à la Justice Pénale nord-américaine.

Mots-clé: viol; violence sexuelle; Justice Pénale comparée; droit comparé; marche de la Justice Pénale 


\title{
As Peças e os Mecanismos do Crime Organizado em Sua Atividade Tráfico de Drogas
}

Adriano Oliveira

\section{INTRODUÇÃO}

\begin{abstract}
atuação do crime organizado em suas mais diversas atividades A vem sendo mostrada diariamente pelos órgãos de comunicação, em conseqüência das ações das instituições coercitivas - compreendendo-se por instituições coercitivas as Polícias, o Ministério Público, o Poder Judiciário e os Tribunais de Contas do Estado e da União. Tráfico de drogas, roubo a bancos, seqüestros, corrupção pública e rebelião em presídios são algumas das atividades dos grupos criminosos no Brasil. Contudo, apesar de o termo crime organizado ser amplamente usado por diversos autores, inclusive em obras acadêmicas, observam-se a ausência da sua definição e a explicação da sua dinâmica e seus mecanismos de atuação.
\end{abstract}

Mingardi (1996; 1998), Zaluar (1994; 2002; 2004), Rodrigues (2002; 2003), Procópio (1999) e Machado (2002) são pesquisadores que abordaram a criminalidade organizada em suas mais diversas atividades, mas não construíram uma definição objetiva do que seja crime organizado nem explicaram seus mecanismos.

Por meio de uma revisão da literatura, Mingardi aponta as características presentes em atividades criminais que devem ser reconhecidas como de organizações criminosas. Suas pesquisas abarcam as ações de

DADOS - Revista de Ciências Sociais, Rio de Janeiro, Vol. 50, n-4 4, 2007, pp. 699 a 720. 